\title{
Prognostic value of coronary vessel dominance in relation to significant coronary artery disease determined with non-invasive computed tomography coronary angiography
}

\author{
Caroline E. Veltman ${ }^{1,2 *}$, Fleur R. de Graaf ${ }^{1}$, Joanne D. Schuijf ${ }^{1}$, \\ Jacob M. van Werkhoven ${ }^{1}$, J. Wouter Jukema ${ }^{1,2}$, Philipp A. Kaufmann ${ }^{3,4}$, \\ Aju P. Pazhenkottil ${ }^{3}$, Lucia J. Kroft ${ }^{5}$, Eric Boersma ${ }^{6}$, Jeroen J. Bax ${ }^{1}$, Martin J. Schalij ${ }^{1}$, \\ and Ernst E. van der Wall ${ }^{1,2}$
}

\begin{abstract}
${ }^{1}$ Department of Cardiology, Leiden University Medical Center, Albinusdreef 2, 2333 ZA Leiden, The Netherlands; ${ }^{2}$ The Interuniversity Cardiology Institute of the Netherlands (ICIN), Utrecht, The Netherlands; ${ }^{3}$ Cardiac Imaging, University Hospital Zurich, Zurich, Switzerland; ${ }^{4}$ Zurich Center for Integrative Human Physiology (ZIHP), Zurich, Switzerland; ${ }^{5}$ Department of Radiology, Leiden University Medical Center, Leiden, The Netherlands; and ${ }^{6}$ Department of Cardiology, Erasmus Medical Center, Rotterdam, The Netherlands
\end{abstract}

Received 7 June 2011; revised 12 January 2012; accepted 1 February 2012; online publish-ahead-of-print 4 March 2012

Aims

Limited information is available regarding the relationship between coronary vessel dominance and prognosis. Therefore, the purpose of this study was to determine the prognostic value of coronary vessel dominance in relation to significant coronary artery disease (CAD) in patients referred for computed tomography coronary angiography (CTA).

Methods and results

The study population consisted of 1425 patients ( 869 men, $57 \pm 12$ years) referred for CTA. To evaluate the impact of vessel dominance and significant CAD on CTA on outcome, patients were followed during a median period of 24 months for the occurrence of non-fatal myocardial infarction and all-cause mortality. The presence of a left dominant system was identified as a significant predictor for non-fatal myocardial infarction and all-cause mortality (HR: 3.20; $95 \% \mathrm{Cl}: 1.67-6.13, P<0.001)$ and had incremental value over baseline risk factors and severity of CAD on CTA. In addition, in the subgroup of patients with significant CAD on CTA, patients with a left dominant system had a worse outcome compared with patients with a right dominant system (cumulative event rates: $9.5 \%$ and $35 \%$ at 3 -year follow-up for a right and left dominant coronary artery system, respectively, log-rank $P<0.001$ ).

Conclusions The presence of a left dominant system was identified as an independent predictor of non-fatal myocardial infarction and all-cause mortality, especially in patients with significant CAD on CTA. Therefore, the assessment of coronary vessel dominance on CTA may further enhance risk stratification beyond the assessment of significant CAD on CTA.

Keywords Computed tomography coronary angiography • Coronary vessel dominance • Coronary artery disease • Prognosis - Risk stratification

\section{Introduction}

Non-invasive computed tomography coronary angiography (CTA) is increasingly used in clinical practice for visualization of the coronary arteries in patients with suspected or known coronary artery disease (CAD). ${ }^{1-3}$ Multiple studies demonstrated high diagnostic accuracy of CTA in detection of CAD. In addition to the good diagnostic performance, CTA also provides important prognostic information. ${ }^{4,5}$ Several studies have shown that patients with significant CAD detected on CTA have worse overall outcome compared with patients without significant CAD., However, CTA not only provides information about the presence

* Corresponding author. Tel: +310 71 5262020, Fax: +310 71 5266809, Email: c.e.veltman@lumc.nl

Published on behalf of the European Society of Cardiology. All rights reserved. (C) The Author 2012. For permissions please email: journals.permissions@oup.com 
and degree of coronary stenosis, it also allows the evaluation of cardiac anatomy including coronary vessel dominance. As a result, coronary vessel dominance is routinely determined on CTA. In the general population, a right dominant coronary artery system is most prevalent, $\sim 87-89 \%$, while a left dominant coronary artery system has a prevalence of $7-8 \%$ and a balanced coronary artery system is present in $\sim 4 \%$ of the population. ${ }^{8-10}$ Although coronary vesssel dominance is easily assessed on CTA, limited information is available considering the prognostic value of coronary vessel dominance in patients referred for CTA. Moreover, the relationship between coronary vessel dominance and the prognostic importance of a significant stenosis remains unclear. Therefore, the purpose of this study was to evaluate the prognostic relevance of coronary vessel dominance in the presence and absence of CAD determined on CTA.

\section{Methods}

\section{Patients and study protocol}

The study population consisted of consecutive patients who were clinically referred for CTA because of typical chest pain or atypical chest pain in combination with an elevated risk profile for cardiovascular disease. Patients were enrolled at the Leiden University Medical Center in the Netherlands and at the University Hospital Zurich in Switzerland. Exclusion criteria were: (i) previous coronary artery bypass graft surgery (CABG); (ii) (supra)ventricular arrhythmias; (iii) renal insufficiency (defined as a glomerular filtration rate $<30 \mathrm{~mL} /$ min); (iv) known allergy to iodinated contrast agent; (v) severe claustrophobia; and (vi) pregnancy. Patient data were entered consecutively into the departmental patient information systems and retrospectively analysed. Patients with uninterpretable CTA examination were excluded from the analysis. Patients referred for revascularization after CTA remained in the study population.

\section{Computed tomography coronary angiography data acquisition}

Patients were scanned using a 64-row CT scanner (Aquillion64, Toshiba Medical Systems, Otawara, Japan; General Electrics LightSpeed VCT, Milwaukee, WI, USA) or with a 320-row CT scanner (Aquilion ONE, Toshiba Medical Systems). Before examination the patient's heart rate and blood pressure were monitored. In the absence of contraindications, patients with a heart rate exceeding 65 b.p.m. received 50 or $100 \mathrm{mg}$ oral metoprolol, or 5-10 mg metoprolol, intravenously. Scan acquisition parameters have been previously described. ${ }^{5,11,12} \mathrm{~A}$ reconstruction data set with the least motion artefacts was evaluated, typically acquired during a mid-diastolic phase.

\section{Computed tomography coronary angiography image analysis}

Computed tomography coronary angiography reconstructions were transferred to dedicated workstations (Vitrea2, Vital Images, USA and Advantage, GE Healthcare, USA). Computed tomography coronary angiography image analysis was performed by two observers in consensus, experienced in the evaluation of CTA. Coronary anatomy and coronary vessel dominance were assessed in a standardized manner by dividing the coronary artery tree into 17 segments according to the guidelines of the American Heart Association. ${ }^{13}$ A coronary artery system was classified as right dominant when the posterior descending artery (PDA) originated from the right coronary artery (RCA), whereas a coronary artery system was considered left dominant if the PDA originated from the left circumflex artery (LCX). A coronary artery system was classified as balanced, when the PDA originated from the RCA in combination with a large posterolateral branch originating from the LCX reaching near the posterior interventricular groove. Subsequently, the presence of CAD was assessed by scrolling through axial images, simultaneous with visual assessment of curved multiplanar reconstructions in at least two orthogonal planes. All 17 coronary segments were scored as (i) normal CTA or minor wall irregularities $<30 \%$, (ii) non-obstructive CAD (defined as $30-50 \%$ luminal narrowing), or (iii) significant $C A D$ (defined as $\geq 50 \%$ luminal narrowing), as previously described. ${ }^{5}$ In case of stented coronary segments, the presence of in-stent restenosis was analysed as described before. ${ }^{14,15}$ Computed tomography coronary angiography results on a per patient basis were scored according to the five-step score assessing both degree of stenosis and number of vessels affected, as previously described by Chow et al. ${ }^{16}$ The five categories were normal coronaries or minimal wall irregularities $<30 \%$, non-obstructive CAD, and one-, two-, and three-vessel disease.

\section{Patient follow-up}

Patients were entered prospectively into the departmental patient information system over a period of 3 years. Follow-up information was obtained for all patients 6 months post-index CTA of the last patient entering the study. Based on the difference in inclusion date, the follow-up time varied among patients with a minimal follow-up time of 6 months and a maximal follow-up time of 3.5 years. Patient followup data were gathered by three observers blinded to the baseline CTA results using clinical visits or standardized telephone interviews.

\section{Outcome measures}

The primary endpoint was the composite of non-fatal myocardial infarction (MI) and all-cause mortality. Non-fatal MI was defined based on the criteria of typical chest pain, elevated cardiac enzyme levels, and typical changes on the ECG. ${ }^{17}$ A secondary outcome was the occurrence of cardiac adverse events, defined as the composite of nonfatal $\mathrm{Ml}$ and cardiac death. To obtain the cause of death, the electronic health records of the cardiology department were first consulted. If the cause of death could not be retrieved from these health records, general practitioners were contacted. Cases that remained unidentified were classified as unknown.

\section{Statistical analysis}

Continuous variables were expressed as means and standard deviations (SD) and categorical baseline data were expressed in numbers and percentages. Kaplan-Meier analyses stratified for coronary vessel dominance were performed to estimate the cumulative incidences of the primary and secondary endpoints in the total population, in patients without significant CAD on CTA and in patients with significant CAD on CTA. Annual event rates were calculated by dividing the Kaplan-Meier event rates by the mean number of years of follow-up.

Subsequently, Cox regression analysis for the primary and secondary endpoints was used to determine the prognostic value of coronary vessel dominance and CAD on CTA. The number of covariables included in the multivariate analysis was adjusted to the number of events. According to univariate significance and baseline differences between groups, age, smoking, and diabetes were included in the multivariate model, together with the confounding factors of gender and known CAD. The increase in global Chi-square values was used to determine the incremental prognostic value of coronary vessel dominance over CAD on CTA and clinical risk factors. To avoid the 
potential of overfitting in this extensive multivariate Cox regression model, two additional models were created only correcting for age, gender, and overall plaque burden (model 1) and for age, gender, and proximally located CAD (model 3). Furthermore, the prognostic value of significant stenosis location was determined for all patients, patients with a right dominant coronary artery system and patients with a left dominant coronary artery system. Adjusted hazard ratios (HRs) with 95\% confidence intervals $(\mathrm{Cls})$ were reported. Statistical analysis was performed using SPSS software (version 16.0, SPSS, Inc., Chicago, IL, USA). A $P$-value $<0.05$, by a two-sided test, was considered statistically significant.

\section{Results}

\section{Patient population}

The study population consisted of 1467 consecutive patients clinically referred for CTA at the Leiden University Medical Center $(n=999,68 \%)$ and at the University Hospital Zurich $(n=468$, $32 \%)$. In the total population, the CTA examination was uninterpretable due to poor image quality in $42(2.9 \%)$ patients. As a result, a total of 1425 patients ( $57 \pm 12$ years old, $58 \%$ men) remained for the analysis. In total, 1256 patients (88\%) had a right dominant coronary artery system, while 131 patients (9.2\%) had a left dominant and 38 patients $(2.7 \%)$ had a balanced coronary artery system. The baseline characteristics of the patient population, categorized by coronary vessel dominance, are presented in Table 1. Overall baseline characteristics were similar between groups, although significant differences were observed for the presence of diabetes (22, 34, and 45\% for a right, left, and balanced coronary artery system, respectively, $P=0.003$ ).

Follow-up was obtained for 1347 (94.5\%) patients, while 78 (5.5\%) patients were lost to follow-up. The distribution of coronary vessel dominance was comparable between patients with and without complete follow-up. Furthermore, patients lost to followup were younger $(53 \pm 11$ years old $)$, had less hypertension (28.2\%) and diabetes (9.0\%), and were less often known with CAD (3.8\%) compared with patients with follow-up.

\section{Computed tomography coronary angiography results}

Computed tomography coronary angiography was classified as normal CTA or minor wall irregularities <30\% in 503 (35\%) patients, non-significant CAD in 479 (34\%) patients, and significant CAD in 443 (31\%) patients (Table 2). Of those patients with significant CAD on CTA, 246 patients had one-vessel disease, 125 patients had two-vessel disease, and 72 patients were diagnosed with three-vessel disease. Furthermore, the distribution of significant CAD on CTA did not differ significantly among patients with a right dominant, left dominant, and balanced coronary artery systems. However, normal CTA or minor wall irregularities $<30 \%$ were observed less frequently in patients with a right dominant coronary artery system compared with patients with a left dominant and balanced coronary artery system (34, 44, and $45 \%$, respectively, $P=0.031$ ) (Table 2 ). In addition, there was no difference in the extent of CAD, since the number of vessels affected and the overall plaque burden were comparable between groups (Table 2). Specifically looking at significant stenosis location, the prevalence of a significant stenosis in the RCA was higher in patients with a right dominant coronary artery system when compared with patients with a left dominant and balanced coronary artery system $(16,7$, and $8 \%$, respectively, $P=0.020$ ), while the prevalence of a stenosis in the LAD and LCX did not differ among groups (Table 2).

\section{Cardiac events}

During a median follow-up time of 24 months (25-75th percentile: 15-37 months), the composite endpoint occurred in 57 (4.0\%) patients. Specifically, non-fatal $\mathrm{MI}$ was reported in 18 (1.3\%) patients, while cardiac death occurred in $9(0.6 \%)$ patients and $30(2.1 \%)$ patients died due to non-cardiac death. Causes of the 30 non-cardiac deaths were malignancy (6 deaths), sepsis (5 deaths), respiratory insufficiency (4 deaths), vascular events (3 deaths), postoperative non-cardiac complications (3 deaths), and other causes (7 deaths). In two cases the reason of death remained unknown. A total of 120 (8.4\%) patients underwent revascularization. In 87 (6.1\%) revascularisation was performed by percutaneous coronary intervention $(\mathrm{PCl})$, and in $33(2.3 \%)$ by CABG. No differences in referral for coronary revascularization after CTA were observed between the different coronary vessel dominance groups (revascularization rate of 8.6, 7.6 and 5.3\% in patients with right dominant, left dominant, and balanced coronary artery systems, respectively; $P=0.706)$. Peri-procedural complications were observed in four $(0.3 \%)$ patients. These four patients had a right dominant coronary artery system and experienced a nonfatal $\mathrm{MI}$ within 90 days after revascularization by $\mathrm{PCl}$.

\section{Event rates during follow-up in relation to coronary artery disease and coronary vessel dominance on computed tomography coronary angiography}

When comparing the differences in event-free survival in the total study population according to coronary vessel dominance, the cumulative incidence of non-fatal $\mathrm{MI}$ and all-cause mortality after 3 years of follow-up was $17 \%$ in patients with a left dominant coronary artery system, compared with 4.8 and $2.7 \%$ in patients with right dominant and balanced coronary artery systems, respectively (log-rank $P<0.001$; Figure 1). After stratification according to the absence or presence of significant CAD on CTA, patients without significant CAD were shown to have good prognosis with low annual event rates for adverse cardiac events of $0.3 \%$, as well as low annual event rates for the composite of non-fatal $\mathrm{MI}$ and allcause mortality of $0.9 \%$ (Table 3). Furthermore, in patients without significant CAD no significant difference was observed in event-free survival between right dominant and left dominant coronary artery systems, with cumulative event rates of 2.4 and $7.4 \%$ after 3 years of follow-up for a right and left dominant coronary artery system, respectively (log-rank $P=0.106$; Figure $2 A$ ).

However, in patients with significant CAD higher annual event rates were observed for adverse cardiac events and the composite of non-fatal $\mathrm{MI}$ and all-cause death of 2.2 and 3.8\%, respectively (Table 3). In addition, in the subgroup of patients with significant CAD differences in prognosis were observed between patients with a right dominant and left dominant coronary artery system, 
Table I Patient characteristics

\begin{tabular}{|c|c|c|c|c|c|}
\hline & $\begin{array}{l}\text { Total, } \\
n=1425\end{array}$ & $\begin{array}{l}\text { Right dominant, } \\
n=1256\end{array}$ & $\begin{array}{l}\text { Left dominant, } \\
n=131\end{array}$ & $\begin{array}{l}\text { Balanced, } \\
n=38\end{array}$ & $P$-value \\
\hline Gender (male) (\%) & $824(58)$ & $733(58)$ & $74(57)$ & $17(45)$ & 0.233 \\
\hline Age (years) & $57 \pm 12$ & $57 \pm 12$ & $56 \pm 12$ & $54 \pm 15$ & 0.095 \\
\hline \multicolumn{6}{|l|}{ Reason for referral (\%) } \\
\hline Typical chest pain & $213(15)$ & $190(15)$ & $18(14)$ & $5(13)$ & 0.870 \\
\hline $\begin{array}{l}\text { Atypical chest pain and elevated risk } \\
\text { profile }\end{array}$ & $1212(85)$ & $1066(85)$ & $113(86)$ & $33(87)$ & 0.870 \\
\hline \multicolumn{6}{|l|}{ Clinical risk factors (\%) } \\
\hline Diabetes & $338(24)$ & $276(22)$ & $45(34)$ & $17(45)$ & 0.003 \\
\hline Hypercholesterolaemia $^{a}$ & $551(39)$ & 495 (39) & $44(34)$ & $12(32)$ & 0.232 \\
\hline Hypertension $^{b}$ & $683(48)$ & $599(48)$ & $61(47)$ & $23(61)$ & 0.299 \\
\hline Family history of $C A D^{c}$ & $543(38)$ & $476(38)$ & $51(39)$ & $16(42)$ & 0.894 \\
\hline Current smoking & $354(25)$ & $302(24)$ & $43(33)$ & $9(24)$ & 0.102 \\
\hline Obesity (BMI $\geq 30 \mathrm{~kg} / \mathrm{m}^{2}$ ) & $257(18)$ & $222(19)$ & $24(18)$ & $11(29)$ & 0.227 \\
\hline \multicolumn{6}{|l|}{ Known CAD (\%) } \\
\hline Previous myocardial infarction & $126(8.8)$ & $116(9.2)$ & $8(6.1)$ & $2(5.3)$ & 0.357 \\
\hline Previous PCl & $155(11)$ & $140(11.1)$ & $10(7.6)$ & $5(13.2)$ & 0.423 \\
\hline
\end{tabular}

$\mathrm{BMI}$, body mass index; $\mathrm{CAD}$, coronary artery disease; $\mathrm{PCl}$, percutaneous coronary intervention.

Data are presented as mean values \pm SD or $n(\%)$.

${ }^{a}$ Serum total cholesterol $\geq 230 \mathrm{mg} / \mathrm{dL}$ and/or serum triglycerides $\geq 200 \mathrm{mg} / \mathrm{dL}$ or treatment with lipid-lowering drugs.

${ }^{b}$ Defined as systolic blood pressure $\geq 140 \mathrm{mmHg}$ and/or diastolic blood pressure $\geq 90 \mathrm{mmHg}$ and/or the use of antihypertensive medication.

'Defined as the presence of coronary artery disease in first-degree family members at $<55$ years in men and $<65$ years in women.

Table 2 Computed tomography coronary angiography results

\begin{tabular}{|c|c|c|c|c|c|}
\hline & $\begin{array}{l}\text { Total, } \\
n=1425\end{array}$ & $\begin{array}{l}\text { Right dominant, } \\
n=1256\end{array}$ & $\begin{array}{l}\text { Left dominant, } \\
n=131\end{array}$ & $\begin{array}{l}\text { Balanced, } \\
n=38\end{array}$ & $P$-value \\
\hline \multicolumn{6}{|l|}{ CAD on CTA (\%) } \\
\hline $\begin{array}{l}\text { Normal CTA or minor wall irregularities } \\
\quad(<30 \%)\end{array}$ & $503(35)$ & $428(34)$ & $58(44)$ & $17(45)$ & 0.031 \\
\hline Non-significant CAD on CTA (30-50\%) & $479(34)$ & $428(34)$ & $38(29)$ & $13(34)$ & 0.504 \\
\hline Significant CAD on CTA (>50\%) & $443(31)$ & $400(32)$ & $35(27)$ & $8(21)$ & 0.186 \\
\hline One vessel disease $(>50 \%)$ & $246(17)$ & $224(18)$ & $18(14)$ & $4(11)$ & 0.268 \\
\hline Two vessel disease $(>50 \%)$ & $125(8.7)$ & $110(7.7)$ & $13(9.9)$ & $2(5.3)$ & 0.670 \\
\hline Three vessel disease $(>50 \%)$ & $72(5.1)$ & $66(5.3)$ & $4(3.1)$ & $2(5.3)$ & 0.548 \\
\hline \multicolumn{6}{|l|}{ Significant stenosis location (\%) } \\
\hline RCA & $217(15)$ & $205(16)$ & $9(7.2)$ & $3(8.0)$ & 0.020 \\
\hline LM & $27(1.9)$ & $25(2.0)$ & $1(0.8)$ & $1(2.6)$ & 0.325 \\
\hline LAD & $324(23)$ & $290(23)$ & $27(21)$ & $7(18)$ & 0.723 \\
\hline LCX & $163(11)$ & $140(11)$ & $19(15)$ & $4(11)$ & 0.484 \\
\hline \multicolumn{6}{|l|}{ Overall plaque burden } \\
\hline Mean number of diseased segments ( $>30 \%)$ & $3.1 \pm 3.5$ & $3.2 \pm 3.5$ & $2.5 \pm 3.2$ & $3.6 \pm 4.3$ & 0.697 \\
\hline $\begin{array}{l}\text { Mean number of proximal diseased segments } \\
(>30 \%)\end{array}$ & $1.3 \pm 1.4$ & $1.3 \pm 1.4$ & $1.1 \pm 1.3$ & $1.4 \pm 1.5$ & 0.071 \\
\hline
\end{tabular}

CAD, coronary artery disease; CTA, computed tomography coronary angiography; RCA, right coronary artery; LAD, left anterior descending artery; LCX, left circumflex artery; LM, left main artery.

Comparison of CTA results between coronary vessel dominance groups. Data are presented as mean values \pm SD or $n(\%)$. 


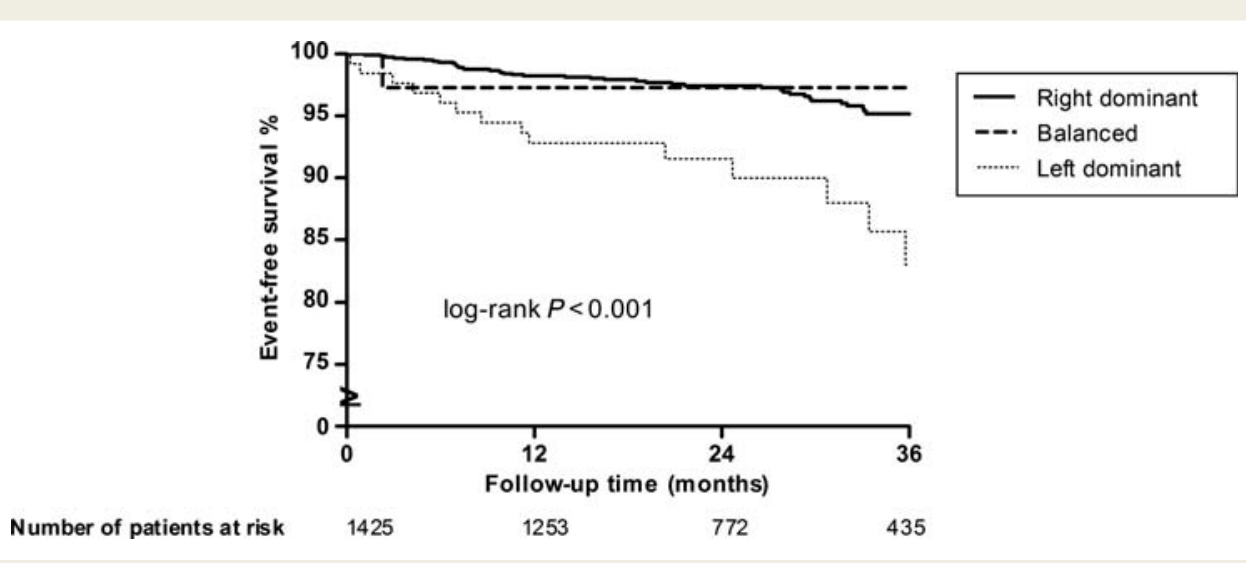

Figure I Kaplan-Meier curve for non-fatal myocardial infarction and all-cause mortality in patients with a right dominant, left dominant, and balanced coronary artery system. In the total study population statistically significant difference in event-free survival according to coronary vessel dominance was observed, showing a worse outcome in patients with a left dominant coronary artery system (log-rank $P<0.001)$.

Table 3 Adverse (cardiac) events in patients with right and left dominant coronary artery systems stratified for significant CAD on CTA

\begin{tabular}{|c|c|c|c|c|c|c|c|c|}
\hline & $n$ & $\begin{array}{l}\text { All } \\
\text { death } \\
(\%)\end{array}$ & $\begin{array}{l}\text { Cardiac } \\
\text { death (\%) }\end{array}$ & $\begin{array}{l}\text { Non-fatal } \\
\text { MI (\%) }\end{array}$ & $\begin{array}{l}\text { Combined } \\
\text { cardiac death, } \\
\text { non-fatal } \\
\text { MI (\%) }\end{array}$ & $\begin{array}{l}\text { Annual } \\
\text { event rate } \\
\text { (\%) }\end{array}$ & $\begin{array}{l}\text { Combined all } \\
\text { death, non-fatal } \\
\text { MI }(\%)\end{array}$ & $\begin{array}{l}\text { Annual } \\
\text { event rate } \\
(\%)\end{array}$ \\
\hline Total & 1387 & $38^{\mathrm{a}}(2.7)$ & $9(0.7)$ & $18(1.2)$ & $27(1.9)$ & 1.0 & $56(4.0)$ & 1.9 \\
\hline Right dominant & 1256 & $27(2.1)$ & $4(0.3)$ & $14(1.1)$ & $18(1.4)$ & 0.8 & $41(3.3)$ & 1.6 \\
\hline Left dominant & 131 & $11(8.4)$ & $5(3.8)$ & $4(3.1)$ & $9(6.9)$ & 2.8 & $15(11.5)$ & 4.5 \\
\hline Log-rank $P$-value & & $<0.001$ & 0.061 & 0.047 & $<0.001$ & & $<0.001$ & \\
\hline No significant CAD & 952 & $15(1.6)$ & $2(0.2)$ & $4(0.4)$ & $6(0.6)$ & 0.3 & $19(2.0)$ & 0.9 \\
\hline Right dominant & 856 & $12(1.4)$ & $2(0.2)$ & $3(0.4)$ & $5(0.6)$ & 0.3 & $15(1.8)$ & 0.8 \\
\hline Left dominant & 96 & $3(3.1)$ & $0(0.0)$ & $1(1.0)$ & $1(1.0)$ & 1.1 & $4(4.2)$ & 2.1 \\
\hline Log-rank $P$-value & & 0.151 & 0.445 & 0.301 & 0.563 & & 0.106 & \\
\hline Significant CAD & 435 & $23(5.3)$ & $7(1.6)$ & $14(3.2)$ & $21(4.8)$ & 2.2 & $37(8.5)$ & 3.8 \\
\hline Right dominant & 400 & $15(3.8)$ & $2(0.5)$ & $11(2.8)$ & $13(3.3)$ & 2.0 & $26(6.5)$ & 3.2 \\
\hline Left dominant & 35 & $8(23)$ & $5(14)$ & $3(8.6)$ & $8(23)$ & 7.9 & $11(31)$ & 9.9 \\
\hline Log-rank $P$-value & & $<0.001$ & 0.010 & 0.059 & $<0.001$ & & $<0.001$ & \\
\hline
\end{tabular}

CAD, coronary artery disease; CTA, computed tomography coronary angiography; MI, myocardial infarction.

Annual event rates were calculated by dividing the Kaplan-Meier event rates by mean number of years of follow-up. Patient with a balanced coronary artery system were excluded from the analysis.

${ }^{a}$ One patient with a balanced coronary artery system without significant CAD on CTA died because of non-cardiac death; accordingly in the total population of 1425 patients, 39 patients died.

because patients with a left dominant coronary artery system showed a significantly worse outcome with a cumulative incidence of non-fatal $\mathrm{Ml}$ and all-cause mortality of $35 \%$ compared with $9.5 \%$ in patients with a right dominant coronary artery system within a follow-up period of 3 years (log-rank $P<0.001$; Figure $2 B$ ).

\section{Incremental prognostic value}

The incremental value of coronary vessel dominance and CAD on CTA was assessed for non-fatal $\mathrm{MI}$ and all-cause mortality (Table 4). A left dominant coronary artery system was identified as a significant predictor of the primary endpoint and remained a significant predictor after correction for baseline risk factors and CAD on CTA, with a HR of 3.20 (95\% Cl: 1.67-6.13, $P<$ 0.001). Balanced coronary artery system did not predict for events (HR: 0.82; 95\% Cl: 0.11-6.05, $P=0.842$ ). In addition, significant CAD in one vessel was also identified as a predictor for non-fatal $\mathrm{MI}$ and all-cause mortality, with a HR of $2.79(95 \% \mathrm{Cl}$ : 1.03-7.60, $P=0.045)$. Subsequently, the risk was increased when more vessels were diseased, with a $\mathrm{HR}$ of $3.59(95 \% \mathrm{Cl}$ : 1.24-10.40, $P=0.019)$ and a $H R$ of $4.14(95 \% \mathrm{Cl}: 1.31-13.06$, 


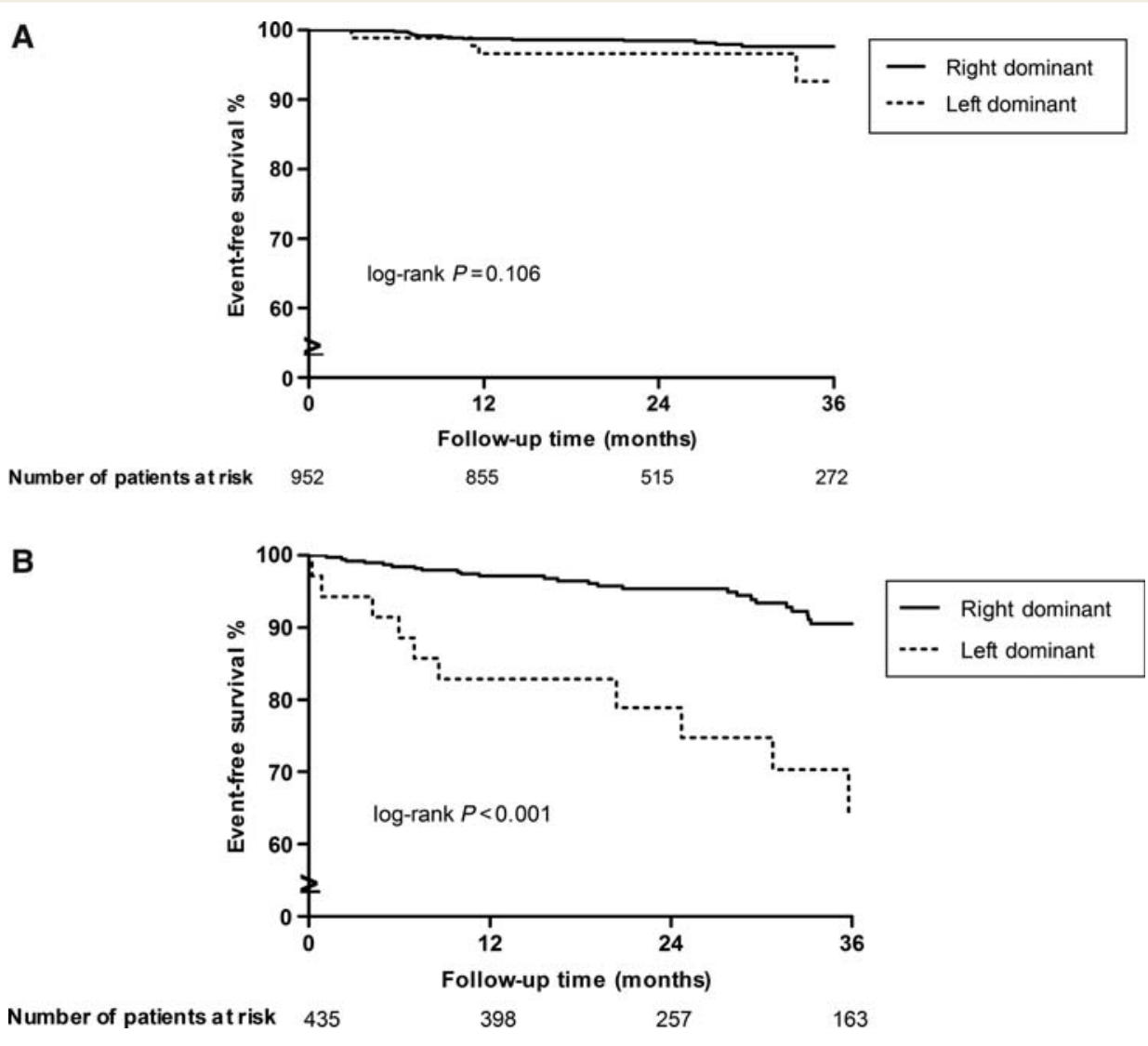

Figure 2 Kaplan-Meier curve for non-fatal myocardial infarction and all-cause mortality in patients with a right dominant and left dominant coronary artery system, stratified for the presence of significant coronary artery disease on computed tomography coronary angiography. (A) Patients without significant coronary artery disease on computed tomography coronary angiography. (B) Patients with significant coronary artery disease on computed tomography coronary angiography. Patients with balanced coronary artery system were excluded from the analysis, because of the low number of patients in this group. Patients without significant coronary artery disease on computed tomography coronary angiography $(A)$ had good event-free survival, showing no statistically significant difference in event-free survival between patients with a left dominant and a right dominant coronary artery system in this patient category (log-rank $P=0.106$ ). In the subgroup of patients with significant coronary artery disease on computed tomography coronary angiography $(B)$, patients with a left dominant coronary artery system had a statistically significant worse outcome compared with patients with a right dominant coronary artery system (log-rank $P<0.001)$. CAD, coronary artery disease; CTA, computed tomography coronary angiography.

$P=0.016)$ for two- and three-vessel disease, respectively. No interaction was observed for the effect of a right dominant vs. left dominant coronary artery system and the absence vs. the presence of significant CAD on CTA for non-fatal $\mathrm{MI}$ and all-cause mortality $(P$-value for interaction $=0.227)$. Furthermore, a significant increase in global Chi-square values confirmed that CAD on CTA had incremental value over clinical risk factors (53.05 vs. $36.32, P=0.025)$ and that coronary vessel dominance had incremental value over CAD and clinical risk factors (65.53 vs. 52.05 , $P=0.006$ ) (Figure 3). Additionally, in reduced Cox regression models a left dominant coronary artery system remained a significant predictor for non-fatal Ml and all-cause mortality with comparable risk estimates, when correcting for overall plaque burden (model 1), proximally located CAD (model 2), and the number of vessels with significant stenosis on CTA (Table 5). Subsequently, overall plaque burden, proximally located $C A D$ and the number of vessels affected were identified as predictors of non-fatal $\mathrm{MI}$ and all-cause mortality with the highest HR of 1.68 (95\% Cl: $1.32-$ 2.14, $P<0.001)$ for the number of vessels affected.

In addition, sub-analysis assessing the independent prognostic value of coronary vessel dominance for the occurrence of nonfatal MI and cardiac death (extensive analysis is not shown) revealed that a left dominant coronary artery system remained a significant predictor of cardiac events (HR between 5.13 and 5.66 when corrected for significant CAD, overall plaque burden, or proximally located CAD, for all analyses $P<0.001)$.

\section{Prognostic value of significant stenosis location}

A stenosis in the left coronary system was observed in 222 patients and was associated with an increased risk of non-fatal $\mathrm{Ml}$ and allcause mortality, with a HR of $2.79(95 \% \mathrm{Cl}: 1.46-5.31, P=$ 0.002) (Table 6). In case of a stenosis in both (right and left) 
Table 4 Multivariate Cox regression analysis for the composite endpoint of non-fatal myocardial infarction and all-cause mortality including clinical risk factors, CTA results and coronary vessel dominance

\begin{tabular}{|c|c|c|}
\hline & HR $(95 \% \mathrm{Cl})$ & $P$-value \\
\hline \multicolumn{3}{|l|}{ Clinical risk factors } \\
\hline Age & $1.06(1.03-1.08)$ & $<0.001$ \\
\hline Gender (male) & $1.33(0.76-2.33)$ & 0.320 \\
\hline Known CAD & $1.25(0.65-2.40)$ & 0.506 \\
\hline Smoking & $3.03(1.79-5.12)$ & $<0.001$ \\
\hline Diabetes & $1.53(0.86-2.72)$ & 0.146 \\
\hline \multicolumn{3}{|l|}{ CTA results } \\
\hline $\begin{array}{l}\text { Normal CTA or minor wall } \\
\text { irregularities }(<30 \%)\end{array}$ & 1.0 (reference) & \\
\hline Non-significant CAD (30-50\%) & $1.44(0.53-3.88)$ & 0.473 \\
\hline One-vessel disease $(>50 \%)$ & $2.79(1.03-7.60)$ & 0.045 \\
\hline Two-vessel disease (>50\%) & $3.59(1.24-10.40)$ & 0.019 \\
\hline Three-vessel disease $(>50 \%)$ & $4.14(1.31-13.06)$ & 0.016 \\
\hline \multicolumn{3}{|l|}{ Coronary vessel dominance } \\
\hline $\begin{array}{l}\text { Right dominant coronary artery } \\
\text { system }\end{array}$ & 1.0 (reference) & \\
\hline $\begin{array}{l}\text { Left dominant coronary artery } \\
\text { system }\end{array}$ & $3.20(1.67-6.13)$ & $<0.001$ \\
\hline Balanced coronary artery system & $0.82(0.11-6.05)$ & 0.842 \\
\hline
\end{tabular}

CAD, coronary artery disease; $\mathrm{Cl}$, confidence interval; CTA, computed tomography coronary angiography; $\mathrm{HR}$, hazard ratio. coronary systems, as was present in 150 patients, a HR of 3.05 (95\% Cl: 1.47-6.31, $P=0.003$ ) was observed. A significant stenosis in the right coronary system, as observed in 63 patients, was not significantly associated with the composite endpoint. Furthermore, in patients with a right dominant coronary artery system, a stenosis in the left coronary system and a stenosis in both (right and left) coronary systems were associated with an increased risk of events with a $\mathrm{HR}$ of $2.41(95 \% \mathrm{Cl}: 1.14-5.12, P=0.022)$ and a HR of 3.12 (95\% Cl: $1.40-6.98, P=0.006)$, respectively. Subsequently, in patients with a left dominant coronary artery system, a stenosis in the left coronary system was associated with an increased risk of non-fatal $M I$ and all-cause death, with a HR of 5.00 (95\% Cl: $1.35-18.43, P=0.016)$. The difference in the risk estimate of a stenosis in the left coronary system in patients with a right dominant and patients with a left dominant coronary artery system was statistically non-significant (HR of 2.4 and HR of 5.0, respectively; $P$-value for interaction $=0.351)$.

\section{Discussion}

This study demonstrated that coronary vessel dominance assessed by CTA has incremental prognostic value and extends the predictive value of CTA. The main finding of the study were that the presence of a left dominant coronary artery system is associated with an increased risk of non-fatal MI and all-cause mortality when

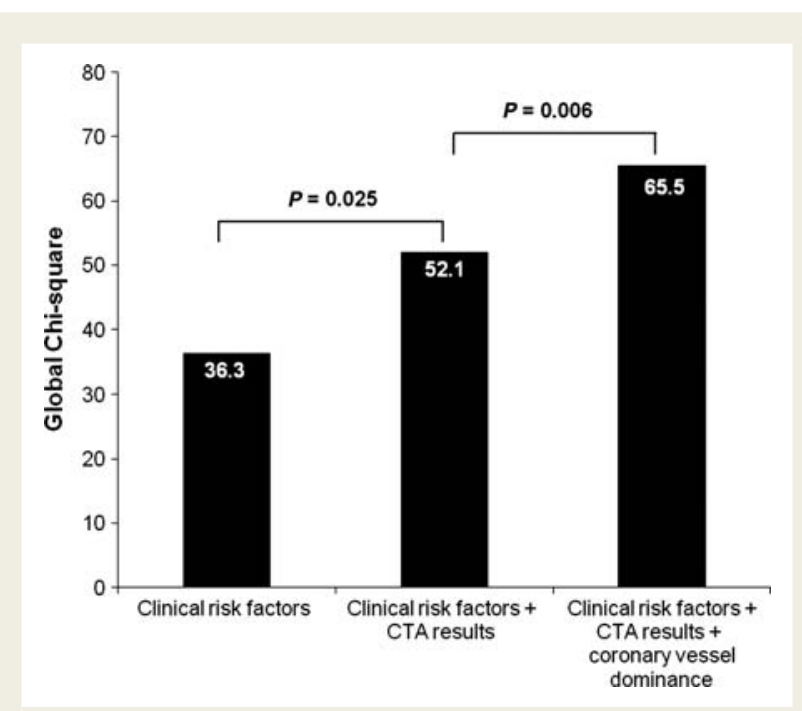

Figure 3 Bar graph illustrating the incremental prognostic value (depicted by $\chi^{2}$ values on the $y$-axis) clinical risk factors, computed tomography coronary angiography results, and coronary vessel dominance. The presence of significant coronary artery disease on computed tomography coronary angiography had a significant incremental prognostic value over the clinical risk factors of age, gender, known coronary artery disease, smoking, and diabetes $(P=0.025)$. A further incremental prognostic value over clinical risk factors and significant coronary artery disease on computed tomography coronary angiography were observed with the addition of coronary vessel dominance $(P=0.006)$. The computed tomography coronary angiography results included in the model consisted of the five categories: normal coronaries or minimal wall irregularities $(<30 \%)$, nonobstructive coronary artery disease (30-50\%) and one-, two-, and three-vessel disease (>50\%). CAD, coronary artery disease; CTA, computed tomography coronary angiography.

compared with a right dominant coronary artery system. Moreover, the presence of significant CAD on CTA in patients with a left dominant coronary artery system was associated with a worse outcome than significant CAD on CTA in patients with a right dominant coronary artery system. These findings suggest that the assessment of coronary vessel dominance using CTA may further enhance the risk stratification beyond the assessment of the degree of stenosis in patients referred for CTA.

The prognostic value of significant CAD using CTA is well established, and an increased risk of cardiovascular events in patients with significant CAD on CTA has been previously demonstrated. $^{4-6,18,19}$ These findings are confirmed in the present study, showing a higher risk of events in patients with significant CAD on CTA, regardless of coronary vessel dominance. While coronary vessel dominance is routinely assessed using CTA, limited information is available about the prognostic value of coronary vessel dominance in patients referred for CTA. A previous study by Goldberg et al. showed that, in a large cohort of patients ( $n=27289)$ who underwent cardiac catheterization due to acute coronary syndrome, the presence of a left dominant coronary artery system was a predictor of death at a mean follow-up duration of 3.5 years (HR: $1.18,95 \% \mathrm{Cl}: 1.05-1.34) .{ }^{20}$ The prognostic 
Table 5 Reduced Cox regression models of age and gender, CTA results and coronary vessel dominance for the composite endpoint of non-fatal myocardial infarction and all-cause mortality

\begin{tabular}{|c|c|c|}
\hline & HR $(95 \% \mathrm{Cl})$ & $P$-value \\
\hline \multicolumn{3}{|l|}{ Model 1: overall Plaque burden on CTA } \\
\hline Age & $1.05(1.02-1.08)$ & $<0.001$ \\
\hline Gender & $1.28(0.71-2.30)$ & 0.406 \\
\hline $\begin{array}{l}\text { Number of segments diseased } \\
\qquad(>30 \%)\end{array}$ & $1.14(1.06-1.23)$ & $<0.001$ \\
\hline $\begin{array}{l}\text { Left dominant coronary artery } \\
\text { system }\end{array}$ & $3.97(2.11-7.50)$ & $<0.001$ \\
\hline \multicolumn{3}{|c|}{ Model 2: proximally located CAD on CTA } \\
\hline Age & $1.04(1.01-1.07)$ & 0.004 \\
\hline Gender & $1.32(0.74-2.36)$ & 0.341 \\
\hline $\begin{array}{l}\text { Proximal diseased segments } \\
\qquad(>30 \%)\end{array}$ & $1.48(1.20-1.83)$ & $<0.001$ \\
\hline $\begin{array}{l}\text { Left dominant coronary artery } \\
\text { system }\end{array}$ & $3.77(2.00-7.10)$ & $<0.001$ \\
\hline \multicolumn{3}{|c|}{ Model 3: extent of significant CAD on CTA } \\
\hline Age & $1.04(1.02-1.07)$ & 0.002 \\
\hline Gender & $1.45(0.82-2.56)$ & 0.199 \\
\hline $\begin{array}{l}\text { Number of vessels with significant } \\
\text { stenosis }(>50 \%)\end{array}$ & $1.68(1.32-2.14)$ & $<0.001$ \\
\hline $\begin{array}{l}\text { Left dominant coronary artery } \\
\text { system }\end{array}$ & $3.72(1.98-6.99)$ & $<0.001$ \\
\hline
\end{tabular}

CAD, coronary artery disease; $\mathrm{Cl}$, confidence interval; $\mathrm{CTA}$, computed tomography coronary angiography; $\mathrm{HR}$, hazard ratio.

Overall plaque burden was assessed by the number of diseased segments including all plaques causing $>30 \%$ luminal narrowing (model 1 ). Proximally located CAD was defined as non-significant and significant stenosis in all proximally located segments (model 2). The number of vessels with significant stenosis $(>50 \%)$ included one-, two-, and three-vessel disease and was entered into the models as a continuous variable (model 3)

value of coronary vessel dominance was most pronounced in patients with acute ST-segment elevation MI. It is remarkable that the hazard of the presence of a left dominant coronary artery system was less pronounced in the study by Goldberg et al. compared with the hazard observed in the current study (HR: 3.20, 95\% Cl: 1.67-6.13). However, the study population may have differed substantially between our investigation and the one by Goldberg et al. The event rate in the study population of Goldberg et al. was higher in all coronary vessel dominance groups since their population consisted of high-risk patients, when compared with low- to intermediate-risk patients in our population. Because of the overall worse prognosis in all patients, the difference between groups could be less pronounced. Furthermore, the outcome measure of Goldberg et al. was all-cause mortality, whereas in the present study also non-fatal MI was included as a primary endpoint in addition to all-cause mortality. These differences in study population and outcome are expected to account for the difference in findings between studies. Importantly, the prognostic value of coronary vessel dominance in patients with and without significant CAD was evaluated in the present study.
Patients without significant CAD on CTA were shown to have a good prognosis irrespective of coronary vessel dominance. These findings confirm the excellent prognostic value of a CTA examination without significant CAD. ${ }^{21}$ In addition, this study showed that in patients with significant CAD on CTA the presence of a left dominant coronary artery system significantly increased the risk of non-fatal $\mathrm{Ml}$ and all-cause mortality as well as for adverse cardiac events including cardiac death as confirmed by sub-analysis.

\section{The extent of atherosclerosis in relation to coronary vessel dominance}

Although limited information is currently available regarding the prognostic value of coronary vessel dominance, the relationship between coronary vessel dominance and anatomical variance of the coronary arteries was investigated in several different studies. A study by Dodge et al., evaluating 83 invasive coronary angiograms, demonstrated a smaller RCA diameter and a larger LCX diameter in patients with a left dominant coronary artery system. $^{22}$ In addition, llia et al. found that a long LAD (defined as an LAD wrapped around the apex of the heart) was present in $87 \%$ of patients with a left dominant coronary artery system compared with $47 \%$ of patients with a right dominant coronary artery system. $^{23}$

Futhermore, the relationship between coronary vessel dominance and the extent of CAD remains uncertain as different studies showed opposing results. The aforementioned study by Goldberg et al. showed more extensive CAD in patients with a right dominant coronary artery system as compared with patients with a left dominant coronary artery system. ${ }^{20}$ Similar findings were shown in the study by Vasheghani-Farahani et al., identifying a higher prevalance of three-vessel disease in patients with a right dominant coronary artery system. ${ }^{24}$ However, Balci et al. did not find a significant difference in the extent of significant CAD between patients with a right and left dominant coronary artery system. ${ }^{25}$ Although the current study did not reveal significant differences in the distribution of significant CAD on CTA, normal CTA results or wall irregularities causing $<30 \%$ luminal narrowing were observed less frequently in patients with a right dominant coronary artery system compared with patients with left dominant and balanced coronary artery systems. Still, for the determination of the relationship between the extent of significantly CAD and coronary vessel dominance, more extensive research is required in larger patient populations.

\section{Underlying mechanisms}

At present, little is known about the prognostic value of significant stenosis location in relation to coronary vessel dominance. This study demonstrated that a stenosis in the left coronary system, meaning the LAD and/or LCX, was associated with an increased risk of events, while a stenosis in the RCA did not statistically significant predict events. The hazard of a stenosis in the left coronary system was comparable between patients with a right dominant and left dominant coronary artery system. Still, coronary vessel dominance has influence on the relative contribution of the different coronary arteries to the total left ventricular blood flow. ${ }^{23,26}$ 
Table 6 Cox regression analysis of significant stenosis location for non-fatal myocardial infarction and all-cause mortality in patients with a right dominant and patients with a left dominant coronary artery system

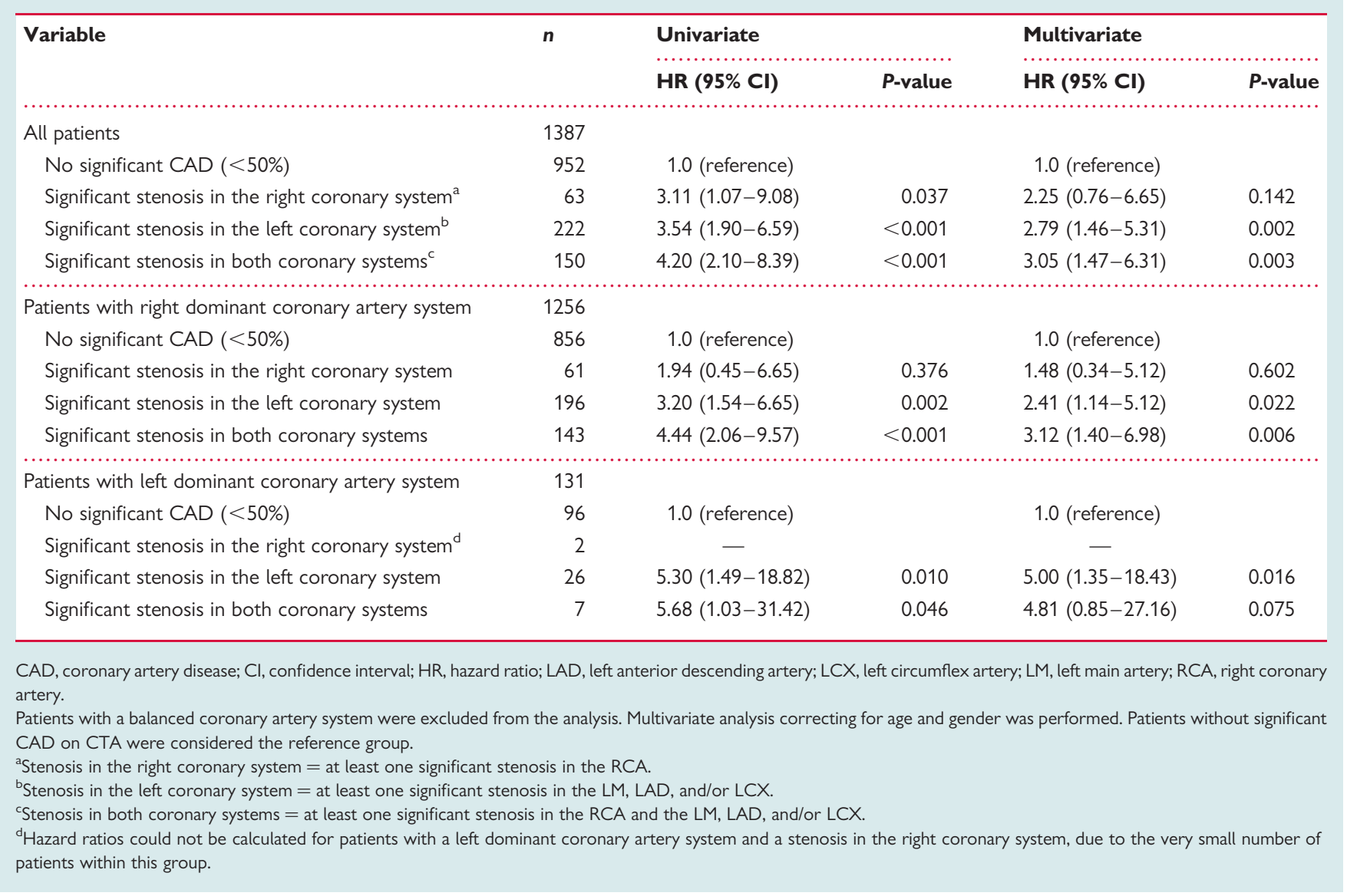

The anatomic importance of a significant stenosis in patients with left dominant coronary artery system might be different from that in patients with a right dominant or balanced coronary artery system. In risk scores the weight factors for a significant stenosis in the segments of the coronary tree differ for patients with a right and a left dominant coronary artery system, with higher scores for the segments of the LAD and LCX in patients with a left dominant coronary artery system. ${ }^{26}$ In patients with a left dominant coronary artery system, the left ventricle receives almost the entire blood supply from the LAD and the LCX, possibly resulting in more extensive $\mathrm{MI}$, in case of a significant stenosis in these vessels. Moreover, the possibility to form collaterals might be less in patients with a left dominant coronary artery system. Since the PDA originating from the RCA is lacking, no collaterals can be formed from the right coronary system, when the left coronary system is suffering from a severe stenosis. At present, however, no studies are available investigating the relationship between coronary vessel dominance and severity of Ml or formation of coronary collateral circulation. Therefore, further research is needed to identify factors contributing to the inferior prognosis of patients with a left dominant coronary artery system.

\section{Clinical implication}

In patients referred for CTA, a left dominant coronary artery system was identified as a significant risk factor for $\mathrm{Ml}$ and death.
Particularly in the subgroup of patients with significant CAD on CTA, those patients with a left dominant coronary artery system had a strongly increased risk of events compared with patients with a right dominant coronary artery system. Therefore, the potential indication for intensive treatment could be more prominent in patients with a left dominant coronary artery system. Furthermore, in case of uncertainty about the need for referral for revascularization, subsequent testing for ischaemia might reveal important information that may assist in clinical decision-making. In current clinical practice, no clear distinction is made in the treatment strategies between patients with a right dominant and a left dominant coronary artery system. When other studies will confirm the results of our study, the knowledge of the prognostic impact of coronary vessel dominance might affect the choice of treatment. Accordingly, the evaluation of coronary vessel dominance could assist in clinical decision making and prognostication in patients referred for CTA.

\section{Limitations}

The current study has several limitations. First, the study was conducted in a relatively small patient population, which results in a comparatively small group of patients with a left dominant coronary artery system, and an even smaller group for patients with a balanced coronary artery system. Of note, the prevalence of right dominant, left dominant, and balanced coronary artery 
systems in the present study population is comparable with that described in the previous literature. ' Because of the small patient groups among patients with significant CAD on CTA, statistically significant difference between the risk estimates for having a significant stenosis in the left coronary systems in patients with a right and a left dominant coronary artery system was not observed, presumably due to insufficient power. Larger studies are needed to elucidate the relationship between significant stenosis location and coronary vessel dominance. Secondly, plaque composition, which may have impact on outcome as well, was not evaluated. In addition, to what extent severely calcified plaques may potentially have influenced the assessment of stenosis severity remains unknown. Thirdly, the multivariate Cox regression model in the current analysis was at the edge of overfitting, due to a relatively low number of clinical events in the present study. However, the Cls observed in the Cox regression analysis were considered reliable and reduced Cox regression models could confirm the prognostic value of coronary vessel dominance. Fourthly, 5.5\% of patients were lost to follow-up. However, no difference in the distribution of coronary vessel dominance was observed in patients without follow-up. Fifthly, because of the relatively low event rate in the current study, larger studies are needed to evaluate the effect of coronary vessel dominance on cardiac adverse events like the composite of non-fatal MI and cardiac death. Instead, the composite of non-fatal $\mathrm{Ml}$ and all-cause mortality was the primary endpoint in the current study. Subsequently, future studies in larger patient cohorts are warranted to confirm these findings.

\section{Conclusions}

The presence of a left dominant coronary artery system is associated with an increased risk of non-fatal $\mathrm{Ml}$ and all-cause mortality. Furthermore, coronary vessel dominance has significant incremental prognostic value over clinical risk factors and significant $C A D$ on CTA. In addition, the presence of significant CAD on CTA in patients with a left dominant coronary artery system is associated with a worse outcome than the presence of significant CAD in patients with a right dominant coronary artery system. Therefore, the assessment of coronary vessel dominance may further enhance risk stratification beyond the assessment of severity and extent of CAD on CTA. However, the underlying mechanism is unknown and its application therefore remains speculative.

\section{Funding}

C.E.V. is financially supported by a research grant from the Interuniversity Cardiology Institute of the Netherlands (ICIN, Utrecht, The Netherlands). F.R.G. is partly supported by the Dutch Technology Foundation STW (Utrecht, the Netherlands), applied science division of NWO and the Technology Program of the Ministry of Economic Affairs, grant no. 10084. P.A.K. is supported by a grant from the Swiss National Science Foundation (SNSF). J.J.B. receives grants from Biotronik, Lantheus medical imaging, Boston Scientific, Edwards Lifesciences, GE Healthcare, Medtronic and St. Jude Medical. M.J.S. receives grants from Biotronik, Boston Scientific \& Medtronic.

Conflict of interest: none declared.

\section{References}

1. de Graaf FR, Schuijf JD, van Velzen JE, Kroft LJ, de RA, Reiber JH, Boersma E, Schalij MJ, Spano F, Jukema JW, van der Wall EE, Bax JJ. Diagnostic accuracy of 320-row multidetector computed tomography coronary angiography in the noninvasive evaluation of significant coronary artery disease. Eur Heart J 2010;31: 1908-1915.

2. Meijboom WB, Meijs MF, Schuijf JD, Cramer MJ, Mollet NR, van Mieghem CA, Nieman K, van Werkhoven JM, Pundziute G, Weustink AC, de Vos AM, Pugliese F, Rensing B, Jukema JW, Bax JJ, Prokop M, Doevendans PA, Hunink MG, Krestin GP, de Feyter PJ. Diagnostic accuracy of 64-slice computed tomography coronary angiography: a prospective, multicenter, multivendor study. J Am Coll Cardiol 2008;52:2135-2144.

3. Miller JM, Rochitte CE, Dewey M, Arbab-Zadeh A, Niinuma H, Gottlieb I, Paul N, Clouse ME, Shapiro EP, Hoe J, Lardo AC, Bush DE, de RA, Cox C, Brinker J, Lima JA. Diagnostic performance of coronary angiography by 64-row CT. N Engl J Med 2008;359:2324-2336.

4. Min JK, Shaw LJ, Devereux RB, Okin PM, Weinsaft JW, Russo DJ, Lippolis NJ, Berman DS, Callister TQ. Prognostic value of multidetector coronary computed tomographic angiography for prediction of all-cause mortality. J Am Coll Cardiol 2007;50:1161-1170.

5. van Werkhoven JM, Schuijf JD, Gaemperli O, Jukema JW, Kroft LJ, Boersma E, Pazhenkottil A, Valenta I, Pundziute G, de RA, van der Wall EE, Kaufmann PA, Bax JJ. Incremental prognostic value of multi-slice computed tomography coronary angiography over coronary artery calcium scoring in patients with suspected coronary artery disease. Eur Heart J 2009;30:2622-2629.

6. Chow BJ, Small G, Yam Y, Chen L, Achenbach S, Al-Mallah M, Berman DS, Budoff MJ, Cademartiri F, Callister TQ, Chang HJ, Cheng V, Chinnaiyan KM, Delago A, Dunning A, Hadamitzky M, Hausleiter J, Kaufmann P, Lin F, Maffei E, Raff GL, Shaw LJ, Villines TC, Min JK. Incremental prognostic value of cardiac computed tomography in coronary artery disease using CONFIRM: COroNary computed tomography angiography evaluation for clinical outcomes: an InteRnational Multicenter registry. Circ Cardiovasc Imaging 2011;4:463-472.

7. Ostrom MP, Gopal A, Ahmadi N, Nasir K, Yang E, Kakadiaris I, Flores F, Mao SS, Budoff MJ. Mortality incidence and the severity of coronary atherosclerosis assessed by computed tomography angiography. J Am Coll Cardiol 2008;52: $1335-1343$.

8. Angelini P, Velasco JA, Flamm S. Coronary anomalies: incidence, pathophysiology, and clinical relevance. Circulation 2002;105:2449-2454.

9. Cademartiri F, La GL, Malago R, Alberghina F, Meijboom WB, Pugliese F, Maffei E, Palumbo AA, Aldrovandi A, Fusaro M, Brambilla V, Coruzzi P, Midiri M, Mollet NR, Krestin GP. Prevalence of anatomical variants and coronary anomalies in 543 consecutive patients studied with 64-slice CT coronary angiography. Eur Radiol 2008;18:781-791.

10. Gorlin R. Coronary anatomy. Major Probl Intern Med 1976;11:40-58.

11. Gaemperli O, Schepis T, Kalff V, Namdar M, Valenta I, Stefani L, Desbiolles L, Leschka S, Husmann L, Alkadhi H, Kaufmann PA. Validation of a new cardiac image fusion software for three-dimensional integration of myocardial perfusion SPECT and stand-alone 64-slice CT angiography. Eur J Nud Med Mol Imaging 2007;34:1097-1106.

12. Schuijf JD, Wijns W, Jukema JW, Atsma DE, de RA, Lamb HJ, Stokkel MP, Dibbets-Schneider P, Decramer I, De BP, van der Wall EE, Vanhoenacker PK, $\mathrm{Bax}$ JJ. Relationship between noninvasive coronary angiography with multi-slice computed tomography and myocardial perfusion imaging. I Am Coll Cardiol 2006;48:2508-2514.

13. Austen WG, Edwards JE, Frye RL, Gensini GG, Gott VL, Griffith LS, McGoon DC, Murphy ML, Roe BB. A reporting system on patients evaluated for coronary artery disease. Report of the Ad Hoc Committee for Grading of Coronary Artery Disease, Council on Cardiovascular Surgery, American Heart Association. Circulation 1975;51:5-40.

14. de Graaf FR, Schuijf JD, van Velzen JE, Boogers MJ, Kroft LJ, de RA, Reiber JH, Sieders A, Spano F, Jukema JW, Schalij MJ, van der Wall EE, Bax JJ. Diagnostic accuracy of 320-row multidetector computed tomography coronary angiography to noninvasively assess in-stent restenosis. Invest Radiol 2010;45: $331-340$.

15. Schuijf JD, Pundziute G, Jukema JW, Lamb HJ, Tuinenburg JC, van der Hoeven BL, de RA, Reiber JH, van der Wall EE, Schalij MJ, Bax JJ. Evaluation of patients with previous coronary stent implantation with 64-section CT. Radiology 2007;245: 416-423.

16. Chow BJ, Wells GA, Chen L, Yam Y, Galiwango P, Abraham A, Sheth T, Dennie C, Beanlands RS, Ruddy TD. Prognostic value of 64-slice cardiac computed tomography severity of coronary artery disease, coronary atherosclerosis, and left ventricular ejection fraction. J Am Coll Cardiol 2010;55:1017-1028.

17. Thygesen K, Alpert JS, White HD. Universal definition of myocardial infarction. Eur Heart J 2007;28:2525-2538. 
18. Buechel RR, Pazhenkottil AP, Herzog BA, Brueckner M, Nkoulou R, Ghadri JR, Kuest SM, Wyss CA, Husmann L, Kaufmann PA. Prognostic performance of low-dose coronary CT angiography with prospective ECG triggering. Heart 2011;97:1385-1390

19. Gaemperli O, Valenta I, Schepis T, Husmann L, Scheffel H, Desbiolles L, Leschka S, Alkadhi H, Kaufmann PA. Coronary 64-slice CT angiography predicts outcome in patients with known or suspected coronary artery disease. Eur Radiol 2008;18:1162-1173.

20. Goldberg A, Southern DA, Galbraith PD, Traboulsi M, Knudtson ML, Ghali WA. Coronary dominance and prognosis of patients with acute coronary syndrome. Am Heart J 2007;154:1116-1122.

21. Abdulla J, Asferg C, Kofoed KF. Prognostic value of absence or presence of coronary artery disease determined by 64-slice computed tomography coronary angiography: a systematic review and meta-analysis. Int J Cardiovasc Imaging 2011;27:413-420.
22. Dodge JT Jr, Brown BG, Bolson EL, Dodge HT. Lumen diameter of normal human coronary arteries. Influence of age, sex, anatomic variation, and left ventricular hypertrophy or dilation. Circulation 1992;86:232-246.

23. Ilia R, Rosenshtein G, Weinstein J, Cafri C, Abu-Ful A, Gueron M. Left anterior descending artery length in left and right coronary artery dominance. Coron Artery Dis 2001;12:77-78.

24. Vasheghani-Farahani A, Kassaian SE, Yaminisharif A, Davoodi G, Salarifar M, Amirzadegan A, Darabian S, Fotouhi A, Sadigh G, Razavi SA, Hakki E. The association between coronary arterial dominancy and extent of coronary artery disease in angiography and paraclinical studies. Clin Anat 2008;21:519-523.

25. Balci B, Yilmaz O. Atherosclerotic involvement in patients with left or right dominant coronary circulation. Kardiol Pol 2004;60:564-566.

26. Leaman DM, Brower RW, Meester GT, Serruys P, van den Brand M. Coronary artery atherosclerosis: severity of the disease, severity of angina pectoris and compromised left ventricular function. Circulation 1981;63:285-299. 